\title{
Estimation of Risk in Software Re-engineering Projects
}

\author{
Dr. Aika Ibraheem Kreedy \\ DOI: 10.29322/IJSRP.10.06.2020.p10293 \\ http://dx.doi.org/10.29322/IJSRP.10.06.2020.p10293
}

\begin{abstract}
Although re-engineering is often used as a means to reduce the risk, reduce costs and maintain the operation of deriving the software, but re-engineering cannot avoid risk. Risk is a probability of occurrence of some unwanted and harmful event to the project. These events can result in cost overruns, schedule slippage, or failure to meet their project goals. Simulation is an important technique for calculate the probability of risk in software reengineering projects. This paper is aimed at implementing a simulator in Monte Carlo algorithm and Matlab language which estimates the probability of risk during project completion.
\end{abstract}

Index Terms- reengineering software, risk, Simulation, Monte Carlo, Estimates, probability

\section{INTRODUCTION}

$\mathrm{R}$ isk analysis has become a standard requirement for projects in many organizations. To meet this requirement and avoid crisis situations because of potential risks we must to identify and specify the particular category threads belongs to the category which consist of (Cost, Time delay, performance, maintenance and user satisfaction ).

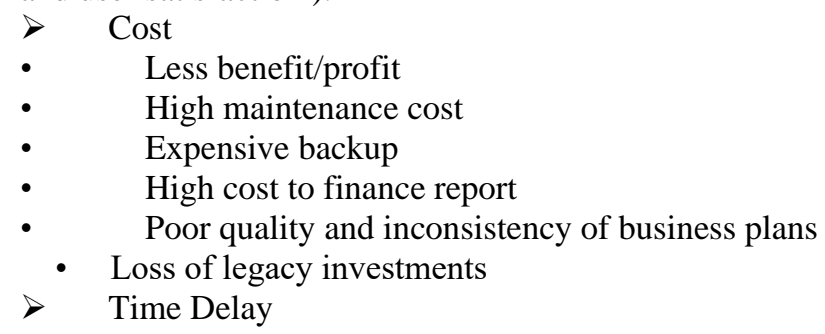

- $\quad$ Lack of knowledge about legacy systems.

- $\quad$ Lack of understanding the concepts of legacy system.

- $\quad$ The vital role played by organizational hierarchy in making decision.

- $\quad$ Political reasons.

- Delivering the project on time.

- Budget cost overflow.

- $\quad$ Migration of team people Performance

- $\quad$ Non portability

- $\quad$ Result mismatching

- Unsupported legacy system

- $\quad$ Reliability mismatch

- $\quad$ Incompatible Result

- Improper selection of reengineering approach

- Inappropriate Data restructuring
D User/Customer Satisfaction: In a competitive marketplace where businesses compete for customers, customer satisfaction is seen as a key differentiator and increasingly has become a key element of any business strategy

And Risk Analysis: During the risk analysis each risk is assessed to determine the probability of risk's occurring, impact of the effect that the resulting problem will have on the project and need to risk associated with activities in the near future would have a higher priority than similar risks in later activities and calculating probability

\section{SIMULATION}

In this paper I have taken a standard example to find $\mathrm{z}$ - value of probability of risks in any software reengineering project. The mathematical table of likelihood of each of the activity performed in an entire duration of project for finding various parameters is also presented. The corresponding statistical result with simulation is also provided to support it.

Monte Carlo algorithm is used for simulation of randomized numbers which are independent and identically distributed. In our case it is used to evaluate the risks that are not achieving its prior deadline. Following are the steps to perform it.

Step1: Start

Step2: Calculate activity time for a given project network multiple times.

Step3: In calculating activity time select activities randomly from a set of estimates. Here, we can use Box-Muller transformation method.

Step4: Output- Range of estimates with associated probabilities

\section{Graph1: Effort in Staff-months After applying Estimate Equation of COCOMO II estimation model-}

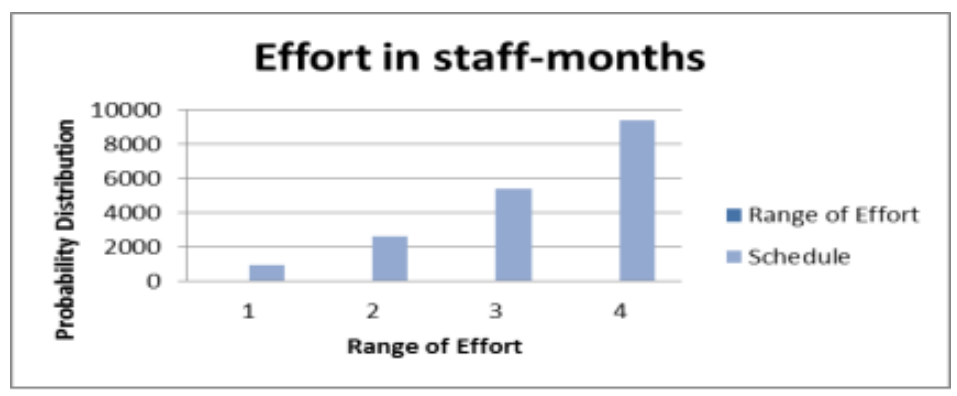


Graph2: Monte Carlo estimation

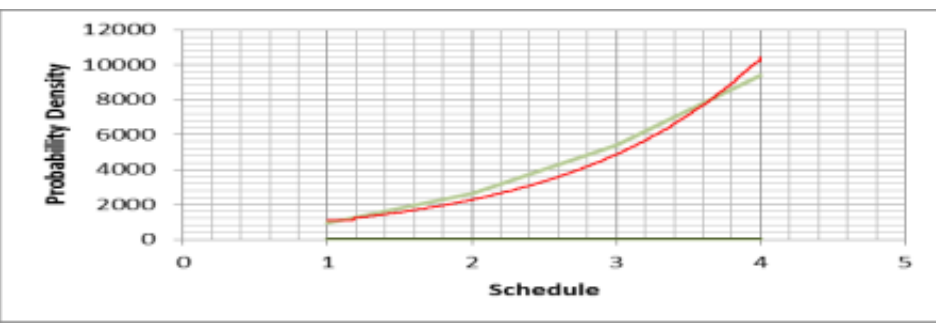

\section{Simulation of a standard example in a software reengineering project}

In a corporation which produces software products develops in this manner, first we look create an activity network with different time estimates, then find mean, variance for it. Our Table 1 shows this.

Table (1): Empirical Time Estimates, Average Mean Time, Variance

\begin{tabular}{|l|l|l|l|l|l|}
\hline Action & Optimistic Time & Most Likely Time & Pessimistic Time & Mean Time & Variance \\
\hline $1-3$ & 2 & 4 & 6 & 4.00 & 2.6 \\
\hline $1-2$ & 3 & 6 & 8 & 5.66 & 4.2 \\
\hline $2-4$ & 5 & 7 & 9 & 7.00 & 2.7 \\
\hline $2-5$ & 4 & 6 & 9 & 6.33 & 4.2 \\
\hline $3-6$ & 6 & 10 & 12 & 9.33 & 6.2 \\
\hline $3-5$ & 3 & 5 & 9 & 5.66 & 6.2 \\
\hline
\end{tabular}

Mean Time, Variance, z-value is calculated using following MATLAB implementation program:

$\%$ Uniform Random Number

$\%$ Monte Carlo method as an approximated integration technique $\%$ integrate $\mathrm{f}(\mathrm{x})$ on the $[0,1]$ interval

clc;

$\mathrm{n}=50$;

$\mathrm{x}=\operatorname{rand}(\mathrm{n}, 1)$;

$\operatorname{gav}=\operatorname{zeros}(\mathrm{n}, 3)$;

gavvar $=\mathrm{NaN}(\mathrm{n}, 3)$;

$\operatorname{gav}(1,1)=x(1,1)$;

$\operatorname{gav}(1,2)=x(1,1)^{\wedge} 2$;

$\operatorname{gav}(1,3)=\cos \left(\mathrm{pi}^{*} \mathrm{x}(1,1)\right)$;

for $\mathrm{i}=2: \mathrm{n}$

$\operatorname{gav}(\mathrm{i}, 1)=\operatorname{sum}(\mathrm{x}(1: \mathrm{i})) / \mathrm{i}$;

$\operatorname{gav}(\mathrm{i}, 2)=\operatorname{sum}\left(\mathrm{x}(1: \mathrm{i}) .^{\wedge} 2\right) / \mathrm{i}$;

$\operatorname{gav}(\mathrm{i}, 3)=\operatorname{sum}\left(\cos \left(\mathrm{pi}^{*} \mathrm{x}(1: \mathrm{i})\right)\right) / \mathrm{i}$;

$\operatorname{gavvar}(\mathrm{i}, 1)=\operatorname{var}(\mathrm{x}(1: \mathrm{i}))$;

$\operatorname{gavvar}(\mathrm{i}, 2)=\operatorname{var}\left(\mathrm{x}(1: \mathrm{i}) .^{\wedge} 2\right)$;

$\operatorname{gavvar}(\mathrm{i}, 3)=\operatorname{var}\left(\cos \left(\mathrm{pi}^{*} \mathrm{x}(1: \mathrm{i})\right)\right)$;

end

$\% \% \% \% \% \% \% \% \% \% \% \% \% \% \% \%$

variance $\% \% \% \% \% \% \% \% \% \% \% \% \% \% \% \% \% \%$

prompt = 'Input optimistic time of an activity ';

ot $=$ input(prompt)

prompt1 = 'Input most likely time of an activity' ;

mlt $=$ input $($ prompt 1$)$

prompt 2 = 'Input pessimistic time of an activity';

$\mathrm{pt}=$ input(prompt2)

mean $=($ ot + mlt + pt $) / 3$;

$\mathrm{v}=($ power $(($ mean-ot $), 2)+\operatorname{power}(($ mean-mlt $), 2)+\operatorname{power}(($ mean-

pt),2))/3;
$\% \% \% \% \% \% \% \% \% \% \% \% \% \% \% \% \% \% \% \% \%$

$\% \% \% \% \% \% \% \% \% \% \% \% \% \% \% \% \% \% \% \%$

$\%$ prompt $=$ 'Input mean time of any activity ';

$\%$ mean $=$ input $($ prompt $)$

$\%$ prompt 1 = 'Input variance of any activity' ;

$\%$ variance $=$ input $($ prompt 1$)$

$\%$ prompt2 = 'Input Schedule Time';

$\%$ st $=$ input $($ prompt2)

$\mathrm{z}=($ st-mean $) / \mathrm{sqrt}(\mathrm{v})$

$\% \% \% \% \% \% \% \%$ Graphics (mean) $\% \% \% \% \% \% \% \% \% \%$

figure(1);

subplot $(3,1,1)$;

$\operatorname{plot}(\operatorname{gav}(:, 1))$;

line((1:n),ones(n,1)/2,'color','red');

legend('Empirical Average','Theoretical Mean',...

'Location','NorthEastOutside');

title('f( $\mathrm{x})=\mathrm{x}$ ');

$\% \% \% \% \% \% \% \% \% \% \% \% \%$

VALUE) $\% \% \% \% \% \% \% \% \% \%$

GRAPHICS(Z

mean, figure (2);

subplot $(3,1,1)$;

$\operatorname{plot}(\mathrm{z})$;

line((1:n),ones(n,1)/2,'color','red');

legend('z-value','Probability of risk',...

'Location','NorthEastOutside');

title('z-value');

$\%$

Output of the program is given below: 


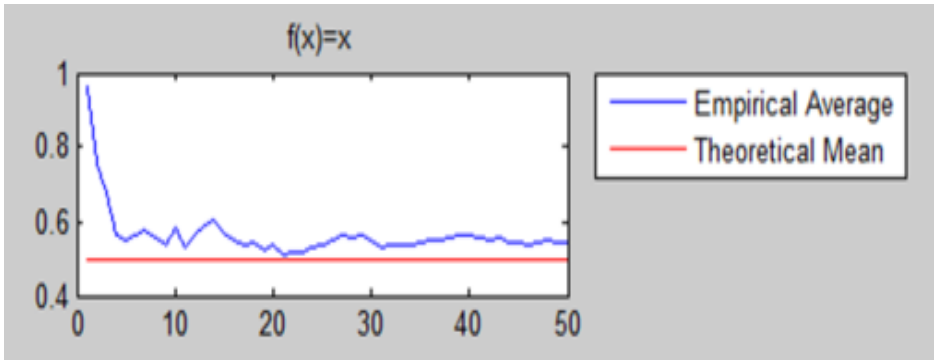

In the next Table 2, we have presented time durations during each simulation run represented as $\mathrm{S}$.

In our case, $\mathrm{s}$ is calculated as follows:

$s=\sqrt{-2 \ln (m n 1) \cos (2 p i \mathrm{X}} r n 2)$

Where, a pair (rn1, rn2) we have taken for random numbers in the range of $(0,1)$.

Table (2) Action and Time Duration

Time Duration

\begin{tabular}{|l|l|l|l|l|l|l|l|l|}
\hline $\mathrm{s}$ & 0.72 & 0.21 & 1.03 & 0.69 & 1.02 & 1.32 & 1.66 & 1.24 \\
\hline Action & \multicolumn{6}{|l|}{ Time Duration of each action is generated } \\
\hline $1-3$ & 9.33 & 7.36 & 8.12 & 9.08 & 7.06 & 5.14 & 6.84 & 7.09 \\
\hline $1-2$ & 7.02 & 8.17 & 8.02 & 8.17 & 6.14 & 8.74 & 9.87 & 8.15 \\
\hline $2-4$ & 5.03 & 7.48 & 6.03 & 6.54 & 5.17 & 9.81 & 7.08 & 9.35 \\
\hline $2-5$ & 6.12 & 8.45 & 7.15 & 7.14 & 6.80 & 7.51 & 9.01 & 9.71 \\
\hline $3-6$ & 5.19 & 6.35 & 8.01 & 8.61 & 7.40 & 6.48 & 8.48 & 6.18 \\
\hline $3-5$ & 6.31 & 5.14 & 9.16 & 8.01 & 8.10 & 5.98 & 7.10 & 7.95 \\
\hline
\end{tabular}

Z-value is used to estimate probability of risk during project completion, calculated as follows:

\section{$Z=\frac{\left(S T-\sum \text { meant ineofcriticalactivities }\right)}{\sqrt{\sum \text { var ianceofcriticalactivities }}}$}

Where, ST= Schedule Time.

Table 3, given below displays several z-value with some project completion time.
Table(3) z- value with project completion time(in percentage)

\begin{tabular}{|l|l|l|l|l|l|l|l|}
\hline $\begin{array}{l}\text { Project } \\
\text { Completi } \\
\text { on Time }\end{array}$ & $\begin{array}{l}27.8 \\
4\end{array}$ & $\begin{array}{l}40.0 \\
1\end{array}$ & $\begin{array}{l}35.7 \\
8\end{array}$ & $\begin{array}{l}41.0 \\
9\end{array}$ & $\begin{array}{l}39.8 \\
7\end{array}$ & $\begin{array}{l}47.0 \\
9\end{array}$ & $\begin{array}{l}39.5 \\
1\end{array}$ \\
\hline z- value & $\begin{array}{l}31.0 \\
0\end{array}$ & $\begin{array}{l}29.3 \\
0\end{array}$ & $\begin{array}{l}41.6 \\
3\end{array}$ & $\begin{array}{l}38.4 \\
5\end{array}$ & $\begin{array}{l}39.5 \\
0\end{array}$ & $\begin{array}{l}41.6 \\
5\end{array}$ & $\begin{array}{l}42.5 \\
4\end{array}$ \\
\hline
\end{tabular}

The next table 4 gives us risk probabilities in percentage (\%) with different values of $s$.

Table(4) risk probabilities in percentage (\%) with different values of $s$.

\begin{tabular}{|l|l|l|l|l|l|l|l|}
\hline $\begin{array}{l}\text { Project } \\
\text { Completion } \\
\text { Time }\end{array}$ & 27.84 & 40.01 & 35.78 & 41.09 & 39.87 & 47.09 & 39.51 \\
\hline z- value & 31.00 & -9.30 & 41.63 & -8.45 & 39.50 & 41.65 & 42.54 \\
\hline $\begin{array}{l}\text { Probability } \\
\text { of Risk }\end{array}$ & 30.01 & 58.14 & 7.33 & 9.15 & 38.50 & 6.11 & 91.25 \\
\hline
\end{tabular}

In the below mentioned graph, I have taken risk probabilities and z-value and shown the relationship between them. 
Graph 1: z-value versus risk probabilities

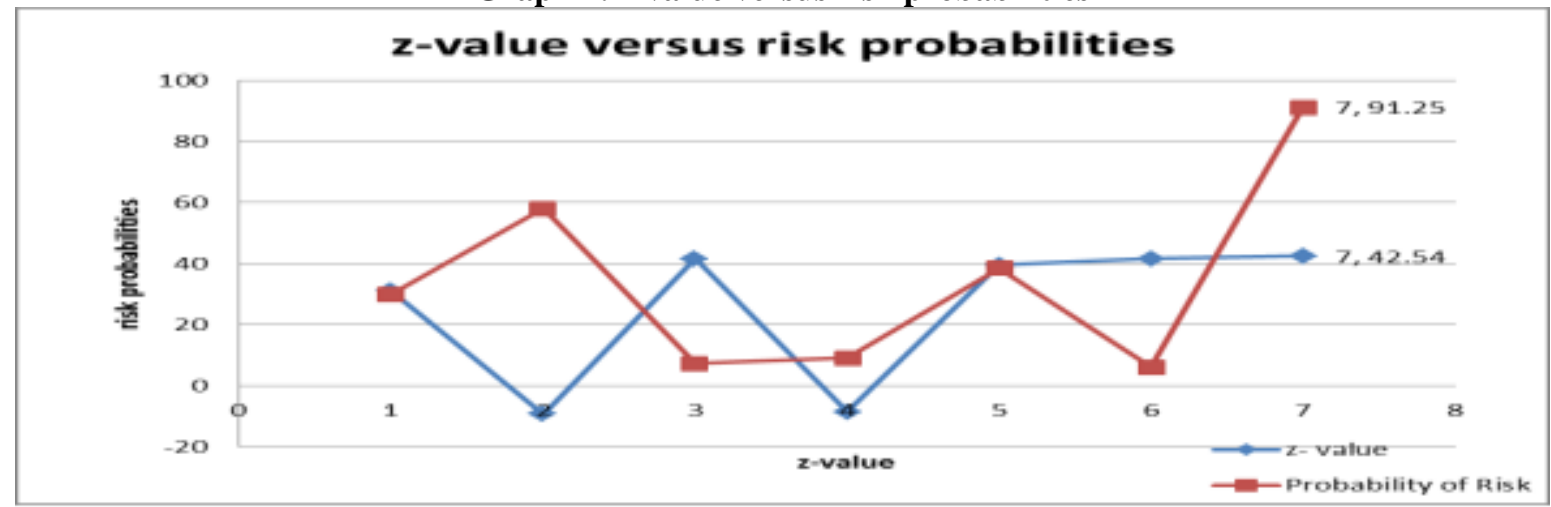

\section{CONCLUSIONS}

We have included mathematical table of each of the time needed in any software reengineering project. We have found statistical result, performed simulation by using Monte-Carlo simulation technique, and derived z-value of probabilities of risks. In the same paper have mentioned the particular algorithm used to do it. And we find from the result the higher the time it takes to complete the project, the smaller is the $\mathrm{z}$ value and the greater is the risk involved in the project. As an alternative to this technique and to provide a greater degree of flexibility in specifying activity durations, we can use MONTE - CARLO SIMULATION Technique to evaluate the risks of not achieving deadlines. It involves calculating activity times for a project network a large number of times, each time selecting activity times randomly from a set of estimates.

\section{REFERENCES}

[1] [1] Dr. P.K.Suri and Pallavi Ranjan (2012): 'Estimating the Probability of Project Completion by SIM_DEL Estimator', International Journal of Computer Science and Information Technologies, Vol. 3 (4), 4938-4945.

[2] [2] Richard E. (Dick) Fairley (2008): 'Risk Management for Software Projects', IEEE Computer Society.

[3] [3] Rodrigues, A. (1996): 'The role of system dynamics in project management', International Journal of Project Management, Vol. 14, No. 4, pp. 213-220.

[4] [4] Roger L. Van Scoy (1992): 'Software Development Risk: Opportunity, not problem', Technical report.

[5] [5] Ronald P. Higuera and Yacov Y. Haimes (1996): 'Software Risk Management', Technical Report CMU/SEI-96-TR-012, Software Engineering Institute.

[6] [6] Severin V. Grabski., Stewart A. Leech., Bai Lu.: 'Risks and Controls in the Implementation of ERP Systems', The International Journal of Digital Accounting Research Vol. 1, No. 1, pp. 47-68

[7] [7] Sneh Prabha and R.L.Ujjawal (2011): 'Software Risk Evaluation and Assessment using Hybrid Approach', Proceedings published in International Journal of Computer Applications.
[8] [8] Undram Chinbat, Soemon Takakuwa (2009): 'using Simulation Analysis for Mining Project Risk Management', Proceedings of the Winter Simulation Conference.

[9] [9] Vinay Kumar Nassa and Sri Krishan Yadav (2012): 'Project Management Efficiency using Soft computing and Risk Analysis', International Journal of Computer Applications (0975 - 8887) Volume 50 - No.16

[10] [10] Yacoub, S.M. and Ammar, H.H., (2002): 'A methodology for architecture level reliability risk analysis', IEEE Transactions on Software Engineering 28 (6), 529-547.

[11] [11] Y.H. Kwak and J. Stoddard (2004): 'Project risk management: lessons learned from software development environment', Technovation.

[12] [12] Young Hoon Kwak and Kenneth Scott LaPlace (2005): 'Examining risk tolerance in project-driven organization', Technovation, 691-695.

[13] [13] Liu Jun, Wang Qiuzhen and Ma Qingguo (2011): 'The effects of project uncertainty and risk management on IS development project performance: A vendor perspective', International Journal of Project Management, 923-933.

[14] [14] Malaya Kumar Nayak, Dr Sanghamitra Mohanty (2012): 'Schedule Risk Analysis of ICT Infrastructure Projects', International Journal of Computer Applications (0975 - 8887) Volume 38- No.5.

[15] [15] Harry M. Sneed : Risks involved in Reengineering Projects

[16] [16] Sneed, H./Kaposi, A.: "A Study on the Effect of Reengineering upon Software Maintainability", in Proc. of ICSM-90, San Diego, IEEE Computer Press, Los Alamitos, 1990, p. 91

[17] [17] Sneed, H.: "Validating Functional Equivalence of Reengineering Programs via Control Path, Result and Data Flow Comparison" in Software Testing, Verification \& Reliability, Vol. 4, No. 1, March 1994, p.33

[18] [18] Sneed, H.: "Regression Testing in Reengineering Projects" in Proc. of 9th Int. Conf. on Testing Computer Software, STAR, Washington, D.C., 1992, p.219

[19] [19] Sneed, H.: "Economics of Software Reengineering" in Journal of Software Maintenance, Vol. 3, No. 3, Sept. 1991, p. 163

[20] [20] Olsem, M.: "An incremental Approach to Software Systems Reengineering", in Journal of Software Maintenance, Vol. 10, No. 3, June 1998 , p. 181

\section{AUTHORS}

First Author - Dr. Aika Ibraheem Kreedy aika.kreedy@yahoo.com 